\title{
Caderno pedagógico como produto educacional do Mestrado Profissional em Educação: contribuições para a formação docente
}

\author{
Pedagogical notebook as the final product of the Professional Master's in Education: \\ contributions to teacher training
}

\section{Cuaderno pedagógico como producto educativo del Máster Profesional en Educación: aportes a la formación del profesorado}

\author{
Teciene Cássia de Souza ${ }^{1}$ \\ Vanilda Aparecida Belizário ${ }^{2}$ \\ Helena Maria Ferreira ${ }^{3}$
}

\section{Resumo}

Com vistas à articulação entre a formação teórica e a atividade docente, os Programas de Pósgraduação em Educação, na modalidade profissional, normalmente, solicitam aos discentes a elaboração de um produto educacional, que possibilite um olhar para o cotidiano da profissão. Entre as várias possibilidades, merecem destaque os cadernos pedagógicos, que proporcionam uma reflexão sobre as contribuições de teorias para a ressignificação das práticas de ensino, bem como a produção autoral de materiais didáticos. Neste artigo, buscou-se discutir as contribuições do processo de proposição de produtos educacionais no âmbito dos programas profissionais, de modo especial, dos cadernos pedagógicos para a formação continuada dos professores da educação básica. Assim, apoiamo-nos em estudos teóricos acerca de produtos finais desenvolvidos nos programas de pós-graduação em educação para contextualizar a discussão proposta. Além disso, é apresentada uma análise de um relato sobre a experiência vivenciada por duas discentes do Programa de Pós-graduação em Educação da Universidade Federal de Lavras (PPGE/UFLA), relativo ao processo de produção de cadernos pedagógicos. Constatou-se que a elaboração desses produtos é fundamental para fortalecer a relação entre universidade e comunidade (escola). Soma-se a isso a constatação de que a elaboração de cadernos pedagógicos constitui uma estratégia formativa notadamente eficaz, por estimular a produção própria de atividades de ensino por parte do professor, um olhar atento para o diagnóstico do nível dos alunos, a seleção de textos, a clareza dos enunciados, a progressão das atividades, a definição de objetivos de ensino, a adequação de metodologias e a eleição de habilidades a serem exploradas, entre outras.

Palavras-chave: Caderno Pedagógico; Mestrado Profissional em Educação; Formação docente.

\footnotetext{
1 Mestra em Educação pela Universidade Federal de Lavras, Nepomuceno, Minas Gerais, Brasil. teciene.souza1@estudante.ufla.br

2 Mestra em Educação pela Universidade Federal de Lavras, Cambuí, Minas Gerais, Brasil. vanilda.marques@estudante.ufla.br

${ }^{3}$ Doutora em Linguística Aplicada e Estudos da Linguagem pela Pontifícia Universidade Católica de São Paulo, Professora associada da Universidade Federal de Lavras, Lavras, Minas Gerais, Brasil. E-mail: helenaferreira@ufla.br
}

Revista Devir Educação, Lavras, vol.5, n2., p.31-48 jul./dez., 2021. 


\begin{abstract}
With the objective of articulating theoretical education and teaching activity, the Graduate Programs in Education, in the professional modality, normally require students to produce an educational product that allows them to look at the daily life of the profession. Among the various product possibilities, the pedagogical notebooks stand out, which provide a reflection on the contributions of theories to the redefinition of teaching practices, as well as the authorial production of teaching materials. In this article, considering the context of the Professional Master's Degree in Education (MPE) of the Federal University of Lavras (UFLA), we sought to discuss the contributions of the production process of educational products within the scope of professional programs, in particular, the pedagogical notebooks for the continuing education of basic education teachers. Thus, we rely on theoretical studies about final products developed in graduate education programs to contextualize the proposed discussion. In addition, an analysis of a report on the experience lived by two PPGE students of Postgraduate Program in Education (PPGE/UFLA) in the production process of pedagogical notebooks is presented. From the analysis carried out, it was found that the elaboration of these products is essential to strengthen the relationship between university and community (school), through continuing education courses for teachers, production of teaching materials, teaching sequences and other possible productions. Added to this is the finding that the production of pedagogical notebooks constitutes a training strategy that is remarkably effective as it stimulates the teacher's own production of teaching activities, a careful look at the diagnosis of the level of students, the selection of texts, the clarity of the statements, the progression of activities, the definition of teaching objectives, the adequacy of methodologies and the choice of skills to be explored, etc.
\end{abstract}

Keywords: Pedagogical Handbook; Professional Master's in Education; Teacher education.

\title{
Resumen
}

Con el objetivo de articular la formación teórica y la actividad docente, los Programas de Posgrado en Educación, en la modalidad profesional, normalmente solicitan a los estudiantes la elaboración de un producto educativo que posibilite uma análisis del contexto de la profesión docente. Entre las diversas posibilidades de producto, merecen destacarse los cuadernos pedagógicos, que brindan una reflexión sobre los aportes de las teorías a la redefinición de las prácticas docentes, así como a la producción autoral de materiales didácticos. En este artículo, considerando el contexto de la Maestría Profesional en Educación (MPE) de la Universidad Federal de Lavras (UFLA), se buscó discutir los aportes del proceso de producción de productos educativos en el ámbito de los programas profesionales, en particular, los cuadernos pedagógicos para la formación continua del profesorado de educación básica. Así, nos apoyamos en estudios teóricos sobre productos finales desarrollados en programas de educación de posgrado para contextualizar la discusión propuesta. Además, se presenta un análisis de un informe sobre la experiencia vivida por dos estudiantes del PPGE (Programa de Posgrado - PPGE / UFLA) en el proceso de producción de cuadernos pedagógicos. A partir del análisis realizado, se encontró que la elaboración de estos productos es fundamental para fortalecer la relación entre universidad y comunidad (escuela), a través de cursos de formación continua para docentes, producción de materiales didácticos, secuencias didácticas y otras posibles producciones. A esto se suma el hallazgo de que la producción de cuadernos pedagógicos constituye una estrategia de formación notablemente efectiva ya que estimula la producción propia del docente de actividades docentes, una mirada atenta al diagnóstico del nivel de los alumnos, la selección de textos, la 
claridad de los enunciados, la progresión de las actividades, la definición de los objetivos docentes, la adecuación de las metodologías y la elección de las habilidades a explorar, etc.

Palavras-clave: Cuaderno pedagógico; Maestría profesional en educación; formación del profesorado.

\section{Introdução}

As pesquisas realizadas no âmbito dos programas de pós-graduação em educação, além que permitirem o avanço das discussões sobre esse campo de conhecimento, podem contribuir, significativamente, para a melhoria dos processos de ensino e de aprendizagem, contemplando a formação continuada de professores, a produção de materiais didáticos, o redimensionamento das metodologias de ensino, a ressignificação da gestão da sala de aula. Nesse contexto, na idealização da proposta de criação de programas profissionais, a Portaria Normativa/Capes n. 17 (2009) ressalta as especificidades da pesquisa nesse percurso formativo, considerando diferentes tipos de produções intelectuais, de acordo com a natureza da área e a finalidade de cada Curso/Programa ${ }^{4}$. Essa questão é relevante para a discussão aqui proposta, uma vez que a criação de produtos pode viabilizar, não somente o enfrentamento de problemas vivenciados pelos professores, mas, também, possibilidades de desenvolvimento profissional, seja por meio de reflexões sobre teorias, seja por meio de análise das práticas pedagógicas. Nessa propositura de articulação entre teoria e prática, o pós-graduando tem a possibilidade, portanto, de apresentar um produto final, além da dissertação. Esse produto pode ser configurado e organizado em diferentes formatos e para diferentes públicos (gestores, professores, pais, alunos etc.)

Em função das potencialidades formativas do processo de criação de produtos educacionais, consideramos que a sistematização de experiências relacionadas a essa estratégia formativa, tal como proposto neste artigo, pode trazer provocações para a qualificação dos modos de organização dos Programas de Pós-graduação em Educação (PPGE), na modalidade profissional, bem como para a articulação com as demandas das

\footnotetext{
${ }^{4}$ De acordo com a Portaria Normativa/Capes n. 17 (2009), o trabalho de conclusão final do curso poderá será apresentado em diferentes formatos, tais como: dissertação, revisão sistemática e aprofundada da literatura, artigo, patente, registros de propriedade intelectual, projetos técnicos, publicações tecnológicas; desenvolvimento de aplicativos, de materiais didáticos e instrucionais e de produtos, processos e técnicas; produção de programas de mídia, editoria, composições, concertos, relatórios finais de pesquisa, softwares, estudos de caso, relatório técnico com regras de sigilo, manual de operação técnica, protocolo experimental ou de aplicação em serviços, proposta de intervenção em procedimentos clínicos ou de serviço pertinente, projeto de aplicação ou adequação tecnológica, protótipos para desenvolvimento ou produção de instrumentos, equipamentos e kits, projetos de inovação tecnológica, produção artística, sem prejuízo de outros formatos, de acordo com a natureza da área e a finalidade do curso, desde que previamente propostos e aprovados pela Capes.
} 


\section{QO DEVIR EDUCAÇÃO \\ ISSN: 2526-849X}

instituições de ensino. Assim, este artigo socializa uma experiência vivenciada por duas egressas do Curso de Mestrado Profissional em Educação da Universidade Federal de Lavras (UFLA), que propuseram, como produto educacional, a elaboração e reelaboração de atividades didáticas voltadas para o estudo de textos multissemióticos, no contexto da Educação Básica, organizado sob o formato de caderno pedagógico.

O produto desenvolvido tomou como ponto de partida as orientações da Base Nacional Comum Curricular - BNCC (BRASIL, 2018), em relação ao trabalho com a leitura e análise de textos multissemióticos, ou seja, textos compostos por diversas semioses (palavras, som, imagem, cores etc.). Em ambos os produtos, foi selecionado, como proposta de trabalho, o gênero videoanimação, a partir do qual foram apresentadas possibilidades de trabalho, nas aulas de Língua Portuguesa, voltadas para os anos finais do ensino fundamental.

A partir do exposto, destacamos que o propósito discursivo deste artigo é refletir sobre as contribuições do processo de criação do produto educacional no PPGE para a formação continuada dos professores da educação básica. Para tanto, apresentaremos uma discussão acerca dos produtos solicitados nos mestrados profissionais que auxiliam na aproximação entre as pesquisas desenvolvidas na universidade e o contexto da escola. Exporemos, ainda, as etapas percorridas para a elaboração do produto final, caderno pedagógico, desenvolvido pelas autoras, egressas do PPGE/UFLA, e, também, um relato de experiência sobre o processo de elaboração do material.

\section{O produto final do Mestrado Profissional e a relação entre Escola e Universidade}

A universidade tem um papel importante para estreitar a relação entre a sociedade e as pesquisas realizadas pelos estudantes da graduação e da pós-graduação. Essa interação, no contexto da pós-graduação, em especial, no contexto dos Programas de Mestrado em Educação, é potencializada pela proposta de, juntamente à dissertação, o discente apresentar um produto final, que pode se configurar em uma sequência didática, um caderno pedagógico, artefatos tecnológicos, proposta de cursos de formação continuada para professores da educação básica etc.

Os produtos educacionais têm, em sua maioria, o objetivo de suprir uma necessidade ou uma lacuna de uma turma ou, até mesmo, do sistema de ensino ou, ainda, apresentar possíveis propostas para o trabalho com uma inovação pedagógica. Desse modo, concordamos com o posicionamento de Gomes e Berg (2013, p. 248):

Revista Devir Educação, Lavras, vol.5, n2., p.31-48 jul./dez., 2021. 


\section{QO DEVIR EDUCAÇÃO \\ ISSN: 2526-849X}

o Mestrado Profissional em Educação ou Ensino privilegia as relações sociais a partir do momento em que convida o pesquisador a este olhar investigativo para o outro, visando não apenas às discussões teóricas, mas também à solução de problemas na Educação Básica. Afinal, a teoria também é importante, mas pode provocar certo distanciamento entre a pesquisa realizada nas universidades e a realidade da escola.

As autoras sinalizam para uma questão notadamente relevante para o campo educacional, qual seja, a dissociação entre teoria e prática. Resguardadas as especificidades dessas duas dimensões, consideramos que a articulação entre elas pode qualificar os processos de ensino e de aprendizagem, bem como a formação profissional, uma vez que as teorias podem ser adequadamente problematizadas a partir da reflexão sobre a prática e, por consequência, validadas, assim como as reflexões sobre as práticas podem ser iluminadas por teorias e, de modo intrínseco, ressignificadas.

Tal como Gomes e Berg (2013), Savegnago et al. (2020, p. 3) também ressaltam a dimensão de atendimento às demandas do contexto educacional por parte dos programas profissionais, conforme se verifica no excerto a seguir. Para os autores, esses programas visam a

capacitar e qualificar profissionais para atender demandas sociais, organizacionais, e do mundo do trabalho; promover a articulação integrada da formação profissional com entidades demandantes de naturezas diversas a fim de melhorar a eficiência e eficácia nas organizações públicas e privadas.

Ao considerarmos os objetivos precípuos dos programas profissionais, notadamente, merece destaque a questão da qualificação profissional, com ênfase para a articulação com a sociedade, com as instituições e com a atividade laboral. No que tange à formação docente, de modo mais específico, essa articulação se efetiva de modo direto com as demandas de gestão educacional/escolar, formação de professores, organização dos processos de ensino e de aprendizagem. Nesse viés, a elaboração de produtos pode contribuir para o processo de formação, uma vez que o pós-graduando terá que partir de uma problematização de uma questão, analisá-la à luz de teoria(s) de pesquisa e propor estratégias de enfrentamento dessa problemática.

Discorrendo sobre essa questão, Gomes e Berg (2013, p. 250) destacam que

os produtos educativos elaborados permitem uma ação direta sobre a Educação Básica, com o professor investigando sua prática pedagógica. As pesquisas do Mestrado Profissional são realmente utilizadas nas salas de aula do Ensino Básico, o que muitas vezes não acontece com os estudos realizados no Mestrado Acadêmico. É a apropriação do papel de pesquisador

Revista Devir Educação, Lavras, vol.5, n2., p.31-48 jul./dez., 2021. 


\section{QO DEVIR EDUCAÇÃO \\ ISSN: 2526-849X}

pelo professor da Educação Básica, que deixa de ser um mero replicador do conhecimento (DEMO, 2010) e passa a agir com intencionalidade em sala de aula.

As autoras apontam para duas questões que consideramos substancialmente relevantes para a discussão aqui proposta, quais sejam: a) a necessária distinção entre programas profissionais e acadêmicos; e b) a formação do professor pesquisador para uma atuação reflexiva. Essas duas questões se configuraram como características basilares para a concepção das especificidades dos programas profissionais.

Em face do exposto e considerando o desenvolvimento de uma pesquisa que, ao final, resultará em um produto que, por sua vez, terá uma ação direta sobre a formação do professor e, também, sobre a Educação Básica, podemos destacar o que nos apresentam Savegnago et al. (2020, p. 4), ao afirmarem que

Os acadêmicos dos mestrados profissionais têm o desafio de empreender pesquisas implicadas e aplicadas com rigor teórico-metodológico para que possam ampliar sua compreensão do contexto investigado como pesquisadores em ambiente natural de trabalho e, posteriormente, desenvolver produtos para contribuir ou intervir nas realidades de atuação profissional.

Os autores ainda fazem uma consideração acerca dos produtos desenvolvidos com as pesquisas do mestrado profissional na área de educação, em que são destacados os produtos e suas possibilidades de intervenções, soluções ou, ainda, encaminhamentos para o professor que irá trabalhar com determinado conteúdo. Enfrentar essa questão se reveste de importância no contexto dos cursos de mestrado em Educação, uma vez que a concepção de produto educacional ainda é emblematicamente caracterizada nos/pelos PPGE, seja em relação às configurações organizacionais, seja em relação à articulação com o projeto de pesquisa desenvolvido.

Nesse sentido, pode haver certo distanciamento entre a pesquisa desenvolvida e as dificuldades vivenciadas pelos professores de Educação Básica. Entre essas dificuldades, Silva, Suarez e Umpierre (2017) destacam: metodologias que dão primazia às abordagens teóricas nas aulas, ensino livresco, ausência do estabelecimento de relações com o saber do cotidiano nas situações de ensino-aprendizagem, matriz curricular hermética e conteúdos desvinculados das demandas dos alunos, modelo de transmissão dos conhecimentos como verdades neutras e absolutas, desinteresse dos alunos pelas aulas, dificuldade de superação das concepções prévias trazidas pelos alunos, abordagens pedagógicas que desconsiderem a 
contextualização histórica e filosófica da construção científica, falta de clareza sobre a função social da alfabetização científico-tecnológica, lacunas na formação inicial do professor, necessidade de se repensar os modelos de formação continuada, falta de articulação entre a formação e a pesquisa, dificuldades para o desenvolvimento de um trabalho interdisciplinar.

Nesse contexto, o produto educacional pode contribuir para minimizar essas dificuldades elencadas pelos autores supracitados, seja como estratégia para a ressignificação da própria prática, seja para ressignificar a prática de outros profissionais, desde que a proposta de desenvolvimento esteja assentada em critérios definidos e em objetivos claros para os professores em formação.

Assim, os produtos educacionais podem contribuir para uma formação docente ativa responsiva, isto é, em que o docente se configure como protagonista de sua própria formação. Nessa perspectiva, Pedro Demo (1996, p. 1) considera que a postura reflexiva do professor pode favorecer um "processo de formação da competência humana com qualidade formal e política, encontrando-se, no conhecimento inovador, a alavanca principal da intervenção da ética" (DEMO, 1996, p. 1). Essa competência apresenta duas dimensões: a técnica (domínio específico da área de atuação profissional do professor) e a política (papel de transformação social no contexto histórico). O autor complementa que

Professor precisa ser formulador de proposta própria, ou seja, precisa saber elaborar com autonomia. Enquanto sua função de socializador do conhecimento decresce e será substituída em grande parte, aumenta o desafio formativo, tipicamente educativo, de fundamentar a emancipação própria e dos alunos. A elaboração própria representa tarefa crucial, em alguns sentidos: a) primeiro, representa a prova de que o professor é formulador, ou seja, detém a competência humana de sujeito histórico capaz de história própria; significa que é apto a fazer avançar o conhecimento, participando desse processo como sujeito, e não apenas como objeto receptivo; b) segundo, a elaboração própria é condição essencial da inovação própria, porquanto somente se muda, o que se elabora; assim como o alimento só se torna energia própria através da digestão, a elaboração é a maneira de fazer o conhecimento tornar-se competência própria; c) terceiro, a elaboração própria é condição imprescindível no processo de aprendizagem, tanto no professor que se faz autor, quanto no aluno que precisa do esforço reconstrutivo para se fazer pesquisador. $\mathrm{O}$ reclamo da elaboração própria não acena apenas para sua face formal técnica, mas sobretudo para sua politicidade: tecer a própria vida com autonomia, constitui-se sujeito do conhecimento, ler autor para se tornar autor (DEMO, 2001, p. 6).

Considerando as potencialidades da proposta de elaboração de produtos educacionais para a formação reflexiva do professor nos sentidos elencados por Demo (2001), 
apresentaremos o relato de experiência acerca da produção de cadernos pedagógicos, como proposto pelo Programa de Pós-graduação em Educação - modalidade profissional, da Universidade Federal de Lavras.

\section{As etapas da elaboração do Caderno Pedagógico no Mestrado Profissional em}

\section{Educação: um processo de formação docente}

Após refletirmos sobre o contexto de produção dos produtos educacionais e sua importância para a formação docente no âmbito dos cursos de mestrados profissionais em Educação, apresentaremos, inicialmente, as etapas de sua elaboração, no contexto do PPGE da UFLA. Assim, se os produtos educacionais da área de ensino devem ser desenvolvidos para utilização em escolas públicas do Estado e do País, visando à melhoria da qualidade do ensino da área específica em que foi desenvolvido, é fundamental que eles sejam aplicados e aplicáveis em situações reais de sala de aula, seja em espaços formais ou não formais de ensino (MOREIRA, 2004).

Nesse sentido, os produtos educacionais devem ser desenvolvidos com base na realidade cotidiana do professor, para que possam potencializar oportunidades formativas para outros professores. No contexto da UFLA, esse é o ponto de partida para essa produção, uma vez que a sala de aula é um importante espaço, não só de ação, mas, também, de indagações, reflexões e pesquisa para o professor. Freire (1996, p. 40) chama a atenção para o fato de que a formação de professores demanda a reflexão crítica sobre a prática. Para o autor, "é pensando criticamente a prática de hoje ou de ontem que se pode melhorar a próxima prática. O próprio discurso teórico, necessário à reflexão crítica, tem de ser de tal modo concreto que quase se confunda com a prática”.

Para essa articulação entre teoria e prática, o autor considera que "não há ensino sem pesquisa e pesquisa sem ensino" (FREIRE, 1996, p. 32). Por meio do ensino, o professor continua aprendendo, buscando, problematizando, ressignificando. Por meio da pesquisa, o professor amplia os saberes, confirma conhecimentos, sistematiza ideias, socializa informações, consolida aprendizagens, conhece novos pressupostos, redimensiona concepções, forma-se e qualifica-se para uma atuação profissional e cidadã.

No entanto, a ação de pesquisar necessita de embasamentos, de conhecimentos construídos, também, a partir das experiências de outros pesquisadores. Assim sendo, é importante que o professor esteja preparado para buscar informações, realizar leituras e 


\section{OO DEVIR EDUCAÇÃO \\ ISSN: 2526-849X}

produções textuais, conhecendo teorias e propostas diversificadas, que servirão como fundamentos para o desenvolvimento profissional.

A partir da proposta de formação de professores com o desenvolvimento de pesquisas, de reflexões sobre a prática e de construção de novas propostas pedagógicas, o PPGE da UFLA proporcionou aos seus alunos-professores experiências no percurso formativo, no decorrer dos anos de 2019 e 2020, com a construção de um produto que fosse inspirado na prática da sala de aula, se fundamentasse nos estudos e oferecesse novas e diferenciadas propostas para sanar as questões que, a princípio, inspiraram sua construção. Essa proposição teve embasamento nos referenciais teóricos direcionados para a formação continuada dos professores e para o desenvolvimento de atividades com linguagens em sala de aula.

Nesse contexto, a elaboração do produto pode favorecer a sistematização de processos vivenciados no percurso formativo e na realização das leituras e das discussões, sejam daquelas relacionadas aos componentes integrantes da matriz curricular, sejam daquelas relacionadas à produção da pesquisa per si. Assim, além da sistematização de referenciais teóricos voltados para a formação docente, a elaboração de produtos busca colocar em diálogo teorias/epistemologias e práticas reflexivas.

A seguir serão expostas as quinze etapas seguidas por duas alunas do PPGE,) no desenvolvimento do produto caderno pedagógico. Essas etapas vão além de fases para a elaboração do produto per si, uma vez que dizem respeito ao percurso formativo dessas exalunas. Assim, concomitantemente à elaboração do caderno pedagógico, as egressas constroem seu conhecimento, (re)significam a sua prática e se descobrem como professoras pesquisadoras.

Quadro 1 - Percurso formativo no Mestrado Profissional em Educação na Universidade Federal de Lavras

\begin{tabular}{|l|l|}
\hline \multicolumn{1}{|c|}{ Procedimentos } & \multicolumn{1}{|c|}{ Descrição } \\
\hline $\begin{array}{l}\text { 1) Leitura sobre os fundamentos teóricos } \\
\text { sobre a teoria dos multiletramentos }\end{array}$ & $\begin{array}{l}\text { Levantamento bibliográfico e produção de um glossário sobre } \\
\text { conceitos basilares da teoria; análise de atividades sob a } \\
\text { perspectiva dos multiletramentos; análise de semioses que } \\
\text { constituem os textos }\end{array}$ \\
\hline 2) Leitura sobre o gênero videoanimação & $\begin{array}{l}\text { Caracterização do gênero e análise de suas potencialidades para o } \\
\text { processo de ensino e de aprendizagem, em textos teóricos } \\
\text { publicados e em sites de busca com reconhecimento acadêmico }\end{array}$ \\
\hline $\begin{array}{l}\text { 3) Leitura dos documentos } \\
\text { parametrizadores do ensino de Língua } \\
\text { Portuguesa }\end{array}$ & $\begin{array}{l}\text { Análise da BNCC - Base Nacional Comum Curricular } \\
\text { (http://basenacionalcomum.mec.gov.br/images/BNCC_EI_EF_11 } \\
\text { 0518_versaofinal_site.pdf), dos PCN - Parâmetros Curriculares } \\
\text { Nacionais } \\
\text { (http://portal.mec.gov.br/seb/arquivos/pdf/portugues.pdf) e do } \\
\text { CRMG - Currículo Referência de Minas Gerais }\end{array}$ \\
\hline
\end{tabular}




\begin{tabular}{|c|c|}
\hline & $\begin{array}{l}\text { (https://drive.google.com/file/d/1ac2_Bg9oDsYet5WhxzMIreNtz } \\
\text { y719UMz/view) }\end{array}$ \\
\hline $\begin{array}{l}\text { 4) Leitura sobre a organização de } \\
\text { Cadernos Pedagógicos }\end{array}$ & $\begin{array}{l}\text { Levantamento bibliográfico sobre o tema e análise de cadernos } \\
\text { pedagógicos, para familiarização com esse tipo de suporte textual }\end{array}$ \\
\hline $\begin{array}{l}\text { 5) Produção de atividades com base nas } \\
\text { competências/habilidades de leitura }\end{array}$ & $\begin{array}{l}\text { Elaboração de atividades pautadas em pressupostos teórico- } \\
\text { metodológicos relacionadas ao ensino de Língua Portuguesa }\end{array}$ \\
\hline $\begin{array}{l}\text { 6) Discussão das atividades no grupo de } \\
\text { estudos e com a professora orientadora }\end{array}$ & $\begin{array}{l}\text { Apresentação de comunicações orais sobre a proposta e a } \\
\text { organização do trabalho, e discussão nos encontros de orientação }\end{array}$ \\
\hline 7) Reelaboração das atividades & $\begin{array}{l}\text { Ajustes na organização das atividades a partir das discussões } \\
\text { realizadas }\end{array}$ \\
\hline $\begin{array}{l}\text { 8) Desenvolvimento de um projeto de } \\
\text { intervenção em uma escola de Educação } \\
\text { Básica }\end{array}$ & $\begin{array}{l}\text { Sistematização da produção do Caderno Pedagógico para ajustes } \\
\text { da proposta, no componente curricular Laboratório de Práticas } \\
\text { Investigativas }\end{array}$ \\
\hline $\begin{array}{l}\text { 9) Apresentação do Seminário de } \\
\text { Pesquisa }\end{array}$ & $\begin{array}{l}\text { Apresentação da dissertação e do Caderno Pedagógico para uma } \\
\text { banca examinadora }\end{array}$ \\
\hline 10) Reelaboração das atividades & $\begin{array}{l}\text { Ajustes na organização das atividades, a partir das discussões } \\
\text { realizadas }\end{array}$ \\
\hline 11) Exame de Qualificação & $\begin{array}{l}\text { Apresentação da dissertação e da proposta do Caderno para a } \\
\text { banca examinadora }\end{array}$ \\
\hline 12) Reelaboração das atividades & Ajustes na organização das atividades, a partir das sugestões \\
\hline $\begin{array}{l}\text { 13) Defesa do Trabalho Final e } \\
\text { Apresentação do Caderno Pedagógico }\end{array}$ & $\begin{array}{l}\text { Apresentação da dissertação e do Caderno Pedagógico para uma } \\
\text { banca examinadora }\end{array}$ \\
\hline 14) Revisão do Caderno Pedagógico & Adequações feitas a partir das sugestões da banca avaliadora \\
\hline 15) Socialização das produções & $\begin{array}{l}\text { Disponibilização da dissertação (Repositório Educacional) e do } \\
\text { caderno (e-book), de produções (capítulos, artigos), apresentação } \\
\text { em eventos e dois cursos de formação de professores. }\end{array}$ \\
\hline
\end{tabular}

Fonte: Belizário et al. (2020, p. 97-99)

A partir do Quadro 1, é possível considerar que o processo de produção do produto educacional implica momentos relevantes para o percurso de formação, seja no que diz respeito à reflexão sobre o material produzido, seja no que diz respeito à socialização do material produzido com outros sujeitos-professores. Assim, o PPGE/UFLA busca incentivar e propiciar uma constante interação com outros interlocutores, de modo a desenvolverem, também, um novo olhar investigativo, por meio de momentos de interlocução e de socialização das produções.

No desenvolvimento desse processo formativo, há uma integração da teoria, a partir da dissertação, e da prática, com a elaboração do caderno pedagógico, uma vez que os estudos teóricos que embasam a dissertação integram-se com as propostas presentes na 
fundamentação das atividades do caderno pedagógico. Sobre a integração entre a teoria e a prática no PPGE, Belizário et al. (2020, p. 100) destacam que

\begin{abstract}
durante a produção do caderno, juntamente com a pesquisa teórica, existe a possibilidade de ouvir diferentes vozes e considerar diferentes olhares sobre o produto. Isso se dá pelo fato de que ao ser produzido em um contexto acadêmico, o material passa pela apreciação do orientador e da banca de avaliação do trabalho, o que faz com que a produção das atividades, que poderão ser aplicadas no contexto educacional, seja realizada de maneira reflexiva, buscando relacionar os estudos apreendidos durante a pesquisa com as propostas de atividades apresentadas, o que garante uma qualificação dos processos de ensino e de aprendizagem, a partir das considerações da professora orientadora e da banca avaliativa.
\end{abstract}

Nesse sentido, notamos a relevância desse percurso formativo para o professor e podemos perceber a importância da pesquisa para o ensino e do ensino para a pesquisa, como afirmado por Freire (1996), ao chamar a atenção para o fato de que se insiste em falar, nos dias atuais, em professor pesquisador. Mas, o autor entende que a presença do "pesquisador no professor não é uma qualidade ou uma forma de ser ou de atuar que se acrescente ao ensino", uma vez que o olhar investigativo, a busca e a pesquisa fazem parte da prática docente (FREIRE, 1996, 32).

Assim, é de fundamental importância a contínua e permanente formação docente para que o professor se perceba, se reconheça e se assuma como pesquisador. Nessa acepção, a proposta da elaboração do produto educacional por parte do PPGE/UFLA, em diversas etapas formativas, vai ao encontro do que Freire (1996) preconizou e defendeu para a formação docente, ou seja, o professor é um pesquisador em sua essência, basta-lhe a oportunidade de se descobrir como tal.

Diante dessas oportunidades de se constituir-se como um professor pesquisador, a produção do caderno pedagógico que, apesar dos desafios para sua elaboração, representa uma oportunidade para a compreensão das especificidades de um programa de pós-graduação em educação, na modalidade profissional, qual seja: mais que produzir uma pesquisa teórica, é preciso buscar estratégias para a compreensão do contexto profissional e para a busca de transformações efetivas nos processos de ensino e de aprendizagem e/ou nos processos de gestão. A partir dessa experiência de produção do caderno pedagógico, serão socializados os desafios e as contribuições do percurso vivenciado.

\title{
Desafios e contribuições da produção do Caderno Pedagógico
}

Revista Devir Educação, Lavras, vol.5, n2., p.31-48 jul./dez., 2021. 
Apresentadas as etapas de elaboração do Caderno Pedagógico desenvolvido por nós, consideramos relevante analisar, de modo reflexivo, esse percurso, a partir dos desafios e das contribuições da experiência de produção de material didático.

Em função da necessidade de aprofundamento no processo de leitura da Base Nacional Comum Curricular (BNCC - BRASIL, 2018), principalmente no que diz respeito à leitura de textos multissemióticos, foi escolhido o gênero videoanimação como objeto de estudo e como ponto de partida para a organização das atividades. A produção do caderno se iniciou no $2^{\circ}$ período do curso de mestrado.

Após esse momento, os desafios começaram a surgir, uma vez que a tarefa de produzir um material para apoio didático, no âmbito do PPGE, exige uma relação das teorias estudadas e investigadas na dissertação com as atividades propostas no caderno. Desse modo, para o trabalho com o gênero videoanimação, detectamos que é possível considerar teorias como a Gramática do Design Visual, a Teoria da Multimodalidade, a Semiótica Social e a Pedagogia dos Multiletramentos, que foram abordadas durante a pesquisa teórica. Com isso, destacamos aqui um dos desafios para a produção do caderno: relacionar e aplicar conceitos teóricos pesquisados e estudados durante a pesquisa teórica e aplicá-los na prática, para o desenvolvimento das atividades e questões, ou seja, integrar pesquisa e ensino.

Outro desafio que podemos ressaltar diz respeito à escolha das videoanimações para estudo e análise, uma vez que esse é um gênero muito diversificado em temas e em quantidade. Desse modo, fez-se necessário um cuidado especial em relação às temáticas que seriam abordadas, posto que as temáticas abordadas pelas videoanimações precisariam estar de acordo com a faixa etária dos alunos a que se destinam os cadernos e, ainda, deveríamos considerar a relação do gênero estudado com outros gêneros multimodais (verbais e nãoverbais). Podemos, portanto, destacar mais um desafio nesse processo: o planejamento e a organização do caderno pedagógico, incluindo o processo de seleção dos materiais a serem explorados, fundamental para o resultado final da produção.

Somando-se ao planejamento e organização do caderno, é importante destacar, como desafio, o processo de estruturação e formatação do caderno. Sabemos que esse é um processo que pode ser considerado fácil, porém, não deixa de desafiar o professor, assim como nos desafiou, uma vez que buscamos utilizar recursos básicos disponíveis no Word.

Outro desafio enfrentado foi o percurso de escrita, que tinha como interlocutores os professores, que poderiam não conhecer os pressupostos teóricos substanciais para a 
compreensão das atividades propostas. Assim, a opção por inserir boxes explicativos foi considerada uma estratégia para a qualificação das interações com os potenciais leitores.

Ante aos desafios enfrentados no decorrer do processo formativo e da elaboração do caderno pedagógico, o professor pesquisador aflorava no desejo de realizar mais leituras, de aprofundar conceitos, de compreender o processo e as estratégias de leitura, de analisar outras videoanimações, de entender a linguagem dos materiais didáticos, de articular com as habilidades de leitura da Base Nacional Comum Curricular, de ampliar os espaços de socialização da pesquisa, de avaliar, ainda que de modo experimental, a aplicação das atividades nas escolas, de dialogar com outros professores de escolas de Educação Básica acerca das atividades propostas. Assim, buscamos assumir o papel de pesquisadoras, de produtoras de conhecimento, a partir, não só de estudos teóricos, mas da reflexão acerca de questões que permeiam o cotidiano do processo educativo. Nesse viés, Bortoni-Ricardo (2008, p. 46) corrobora com essa mudança de papel do professor, ao afirmar que

o professor pesquisador não se vê apenas como um usuário de conhecimento produzido por outros pesquisadores, mas se propõe também a produzir conhecimentos sobre seus problemas profissionais, de forma a melhorar sua prática. O que distingue um professor pesquisador dos demais professores [aqueles que não se perceberam ainda como pesquisadores] é o seu compromisso de refletir sobre a própria prática, buscando reforçar e desenvolver aspectos positivos e superar as próprias deficiências. Para isso ele se mantém aberto a novas estratégias.

Dessa forma, conciliando as atividades inerentes à docência com as atividades de pesquisa, demos continuidade à construção do caderno pedagógico, com o olhar voltado para alunos e professores.

Assim, a partir das inquietantes reflexões e curiosos olhares inerentes ao professor pesquisador, cada uma das etapas da elaboração do caderno foi pensado a partir de dois vieses: um dirigido ao público final: os alunos, e o outro direcionado ao professor, uma vez que o caderno pedagógico apresenta, em sua primeira parte, uma proposta formativa para os docentes, com conceitos básicos sobre o gênero e as teorias presentes em sua proposta, bem como sua integração com as habilidades da área de língua portuguesa da BNCC. Desse modo, além de pensar em uma proposta pedagógica que tivesse significado para os alunos, atentamos para a elaboração de um material, também didático e interessante, para o professor.

Outra questão passível de destaque, como afirmado acima, foi a elaboração de um material visualmente interessante, dentro da ferramenta do pacote Office, o Word. Optamos 
por essa ferramenta, uma vez que é acessível e faz parte do cotidiano de grande parte dos professores e pode ser considerada uma ferramenta tecnológica de baixa complexidade. Então, produzir um caderno pedagógico a partir do Word configurou-se como uma forma de apresentar ao professor uma nova perspectiva de construção de materiais pedagógicos diversificados. Não tivemos a intenção de apresentar uma "receita" para os docentes, mas um material que despertasse o interesse desses profissionais para novos olhares, pesquisas, reflexões e elaboração de diferentes materiais. Nosso propósito, nesse sentido, iria além da apresentação de um material pedagógico; nosso intento foi disponibilizar um produto pedagógico que inspirasse outros professores a produzirem materiais diferenciados, a partir de ferramentas presentes em seu cotidiano.

Esse propósito levou-nos a mais um dos desafios: criar um material visualmente interessante e de conteúdo relevante. A partir desse ponto, passamos a criar um material que mesclasse o verbal com o não verbal e se utilizasse de diversas semioses, como imagens, cores, diagramação e links. Até mesmo o formato do caderno pedagógico teria que ser diferenciado, por exemplo, diagramado como um jornal ou revista, para que causasse impacto no leitor.

Postos esses desafios, seguiram-se outros, de acordo com as etapas formativas: os diálogos com o grupo de pesquisa e a orientadora; a construção de uma proposta de intervenção em uma escola de educação básica e a socialização dos resultados e impressões com os colegas; a apresentação do caderno pedagógico, juntamente com a dissertação para apreciação e orientações de uma banca na disciplina Seminários; nova apresentação para a banca de qualificação; e, por fim, a apresentação para a banca de defesa. Todas essas etapas foram entremeadas pela reflexão acerca da proposta do caderno e a reelaboração das atividades que o compunham ou, em outros termos, uma constante ação-reflexão-ação, que é destacada por Bortoni-Ricardo (2008, p. 48), quando observa que "uma grande vantagem do trabalho do professor pesquisador é que ele resulta em uma 'teoria prática', ou seja, em conhecimento que pode influenciar as ações práticas do professor, permitindo uma operacionalização do processo ação-reflexão-ação".

Assim, todos os desafios se transformaram em aprendizado e conhecimentos constituídos a partir da conjugação da pesquisa teórica e com a reflexão da prática, que resultou no que Bortoni-Ricardo (2008, p. 48) denominou "teoria prática". Essas ações mesclando teoria e prática se tornaram fundamentais para a elaboração e melhoria do conteúdo e da apresentação do caderno pedagógico.

Revista Devir Educação, Lavras, vol.5, n2., p.31-48 jul./dez., 2021. 
Desse modo, apesar dos diversos desafios que surgiram no processo de pesquisa e elaboração do caderno pedagógico, podemos afirmar que o percurso vivenciado contribuiu, de modo substancial, para a formação crítico-reflexiva das professoras pesquisadoras. Por isso, destacamos que as contribuições não são importantes apenas para o processo de ensino e de aprendizagem, que terá um material de apoio para o trabalho com os textos multissemióticos (videoanimações) em sala de aula, mas, também, contribui para o conhecimento teórico das autoras e de outros professores, que terão acesso às questões teóricas de maneira contextualizada e com uma linguagem mais acessível para o professor do Ensino Fundamental.

Nesse contexto, podemos destacar que o fato de os mestrados profissionais recomendarem, em sua maioria, a produção de um produto, representa uma estratégia relevante para o desenvolvimento profissional docente, que implica uma atitude responsiva ativa do professor em relação à ação docente. Nesse ínterim, Marcelo (2009) defende que o desenvolvimento profissional não pode ser uma questão imposta, mas deve estar sob a responsabilidade do professor, que precisa querer investir na profissão e ressignificá-la continuadamente. Considerando que o trabalho docente tem o compromisso de transformar o conhecimento em aprendizagens que sejam relevantes para os alunos, é imprescindível que os docentes se convençam da importância de ampliar, aprofundar e melhorar a sua competência profissional e pessoal.

Nessa direção, o produto educacional proposto possibilitou um aprofundamento nas discussões acerca das concepções de gênero textual/discursivo, habilidades de leitura, organização multissemiótica dos textos, suportes digitais e os novos modos de interação, elaboração de enunciados de questões, efetividade de aprendizagens na definição dos objetivos de ensino, progressão das atividades de ensino, relevância da sistematização acerca das atividades de formação docente, entre outras questões. No que tange ao processo de articulação entre teoria e prática, foi possível redimensionar as habilidades de leitura e de produção de textos, ampliando os letramentos acadêmicos (qualificação dos processos de interpretação, comparação e análise dos textos, da compreensão de conceitos e concepções, da elaboração reflexiva de textos, da fala pública, da apropriação das teorias para uma atuação pautada no ensino de conteúdos e na formação para a cidadania) e os letramentos pedagógicos (análise da proposta da BNCC e suas contribuições para o direcionamento mais sistematizado das atividades de ensino, atenção ao modos de organização do gênero explorado, compreensão da responsabilidade do professor no encaminhamento das atividades 
pedagógicas, discussão acerca das estratégias de exploração dos tempos e dos espaços de ensino e de aprendizagem, reflexão acerca da participação do aluno como sujeito ativo responsivo nas interações com os textos trabalhados e com os demais sujeitos (professores e colegas). Desse modo, compreendemos que as atividades propostas a partir do gênero videoanimação, nos cadernos pedagógicos, possibilitaram deslocamentos em relação aos modos de conceber e de realizar as atividades docentes, o que implicou em uma percepção mais acurada das demandas de formação continuada.

Para além da produção dos cadernos pedagógicos, a produção de relatos reflexivos acerca do percurso formativo, tal como o apresentado neste artigo, possibilitou a sistematização de questões que podem contribuir para a nossa formação reflexiva, bem como de outros leitores que tiverem acesso a essa produção, uma vez que a articulação entre teoria e prática, para além dos pressupostos teóricos e pedagógicos, pressupõe modos de dizer e modos de fazer, que nem sempre se constituem de modo explícito.

\section{Considerações finais}

O objetivo deste artigo foi discutir o percurso de produção de produtos educacionais no âmbito dos programas profissionais, de modo especial, dos cadernos pedagógicos para a formação de professores da educação básica. Desse modo, buscamos apresentar questões relacionadas à produção de duas discentes em seus percursos formativos no PPGE da Universidade Federal de Lavras, com destaque para a relevância da elaboração dos produtos para a relação escola (comunidade) e universidade. A partir do trabalho empreendido, foi possível compreender que os produtos desenvolvidos têm o intuito de suprir uma necessidade ou lacuna do processo de ensino. Além disso, é um momento de exposição dos estudos e pesquisas realizadas sobre determinada temática e teoria(s).

No desenvolvimento deste artigo, buscamos explicitar as etapas de produção do Caderno Pedagógico, produto desenvolvido por duas discentes do PPGE/UFLA. Assim, foram elencadas quinze etapas de desenvolvimento do produto final, desde a preparação teórica até a socialização das produções, que acontece por meio da disponibilização da dissertação e do caderno pedagógico, além das produções acadêmicas relacionadas com o estudo realizado.

Buscamos, ainda, relatar os desafios e as contribuições da produção do caderno pedagógico para a formação docente que, apesar dos desafios, identificamos como um rico momento de produção de conhecimento, relacionando teoria (dissertação) e prática (caderno 
pedagógico). Destacamos que as etapas percorridas para a elaboração do caderno pedagógico transpõem a proposta da construção de um material pedagógico, uma vez que se consolidam como estágios no percurso do processo formativo no PPGE e propiciam um diálogo constante e permanente da teoria com a prática mediada pelas ponderações e orientações dos sujeitos que acompanham o desenvolvimento deste trabalho - professor orientador, professores das bancas onde os trabalhos são apresentados e colegas de curso com os quais o material é socializado. E, em meio a todo esse processo, a reflexão sobre a prática a partir de um aporte teórico sólido oportunizou uma formação consistente e intimamente ligada com a ação docente no cotidiano escolar.

Assim, é possível considerar que os produtos finais solicitados nos PPGE vão muito além de simples obediência de uma exigência do programa. A elaboração desses produtos, sejam eles de qualquer natureza, possibilita um amplo processo de formação continuada, para os mestrandos e para os sujeitos que terão contato com o produto por meio de sua disponibilização para o público além universidade.

Nessa direção, podemos considerar uma ressignificação do conceito de inovação, que se configura, não como a criação de um produto inovador, mas de potencialização de novos modos de conceber e de efetivar as atividades de docência e de formação docente. Nessa configuração, compreender a relação intrínseca entre teoria e prática, a articulação entre conceitos/pressupostos teóricos e o processo de elaboração de materiais didáticos e de desenvolvimento das atividades de ensino, a conjugação entre diferentes linguagens, a organização de diálogos com professores (potenciais leitores dos cadernos pedagógicos) e com alunos (potenciais usuários das atividades propostas) representou um percurso formativo que permitiu ressignificar o quê, como e para quê um professor precisa aprender no contexto de uma formação no âmbito de um programa na modalidade profissional.

Desse modo, a reflexão acerca do percurso formativo de elaboração do produto educacional demonstrou as especificidades de um programa na modalidade profissional, que demanda uma discussão acerca das potencialidades da formação para a melhoria efetiva dos processos de ensino e de aprendizagem, bem como para o desenvolvimento profissional. Assim, os produtos educacionais apresentam contribuições que permitem a sistematização das discussões empreendidas no contexto das disciplinas, nos grupos de pesquisa, nas participações em eventos, nas orientações, nas práticas de leitura dos textos para a produção da dissertação, nas experiências dos projetos de intervenção, nas experiências profissionais, enfim, em diferentes espaços formativos.

Revista Devir Educação, Lavras, vol.5, n2., p.31-48 jul./dez., 2021. 


\section{Referências}

BELIZÁRIO, Vanilda Aparecida et al. Formação de professores e a prática da pesquisa: interlocuções com a perspectiva teórica de Paulo Freire. 2020. In: BORGES, Regilson. Maciel; ELIEZER, Cristina Rezende; FARIA, Alex Junior Bilhoto [Orgs]. Educação, mídia e concepções freirianas: novos diálogos. Cruz Alta, RS: Editora Ilustração. p. 91-105.

BORTONI-RICARDO, Stella Maris O professor pesquisador: introdução à pesquisa qualitativa. São Paulo: Parábola Editorial, 2008.

DEMO, Pedro. Educar pela pesquisa. Campinas: Autores Associados, 1996.

DEMO, Pedro. Professor/ Conhecimento. O professor autor na elaboração de material didático. Secretaria de Estado da Educação do Paraná, 2001. Disponível em:

<http://www.educadores.diaadia.pr.gov.br/arquivos/File/formacao_acao/1semestre_2015/prof essor_autor_anexo1.pdf $>$.

FREIRE, Paulo. Pedagogia da autonomia: saberes necessários à prática educativa. São Paulo, SP: Paz e Terra, 1996.

GOMES, Luciana M. J. Baptista; BERG, Rosana da Silva. Mestrado Profissional: reflexão e ação na educação básica. Polyphonía, Goiânia, v. 24, n. 2, p. 19-28, 2013. Disponível em: <https://www.revistas.ufg.br/sv/article/download/37936/19054/ >. Acesso: 10 nov. 2020.

MARCELO, Carlos. Desenvolvimento Profissional Docente: passado e futuro. Sísifo. Revista de Ciências da Educação. n. 8, p. 7 - 22, jan./abr., 2009. Disponível em: < http://www.unitau.br/files/arquivos/category_1/MARCELO__Desenvolvimento_Profissiona 1_Docente_passado_e_futuro_1386180263.pdf >. Acesso $10 \mathrm{fev} .2021$.

MOREIRA, Marco Antonio. O mestrado (profissional) em ensino. Revista Brasileira de Pós-Graduação, $\quad$ v. $1, \quad$ n. $1, \quad 2004 . \quad$ Disponível em: <http://ojs.rbpg.capes.gov.br/index.php/rbpg/article/view/26>. Acesso em: 22/11/2020.

SAVEGNAGO, Cristiano Lanza et al. Produtos de um mestrado profissional na área da educação: um estado do conhecimento. Revista de Gestão e Avaliação Educacional, Santa Maria, v. 9, n. 18, p. 1-14, 3 jan. 2020. Disponível em: < https://periodicos.ufsm.br/regae/article/view/40662 >. Acesso em: 10 out. 2020.

SILVA, Alcina M. T. Braz da Silva; SUAREZ, Ana Paula Mendes; UMPIERRE, Andrea Borges. Produtos educacionais: uma avaliação necessária. Interacções. n. 44, p. 232-243, 2017. Disponível em: < https://revistas.rcaap.pt/interaccoes/article/view/4108/pdf >. Acesso 20 de abr. 2021.

Recebido em: julho/2021. Aprovado em: outubro/2021. 